\title{
An Intertextual Perspective of Chinese and American Poetry around $1920 \mathrm{~s}^{*}$
}

\author{
Yingjie Guo and Wen Wang \\ School of Foreign Languages, Shaanxi Normal University, Shaanxi Province, China \\ \{guoyingjie \& wwen\}@snnu.edu.cn
}

\begin{abstract}
To have an intertextual perspective of Chinese and American poetry around 1920s, this paper firstly deals with the origins of intertextuality in the west as well as in China, and holds that American poetic texts can not confine themselves within American culture and literature only, nor can Chinese poetic texts limit themselves in a small cosmos of Chinese culture and literature as well. Then the paper attempts to prove that American poetry is intertextual, lying in the fact that with time approaching to 1920s, European traditions still function in the transformation of American poetry. And around 1920s, Chinese classical culture competes with European traditions to make American poetry nationalized. Meanwhile, to show Chinese poetry is intertextual, the paper claims that with time approaching to 1920s, China sustains her poetic traditions continually through referring to the established achievements in the past. And around 1920s, western culture, especially American culture, influenced Chinese poetic traditions to have a change in both inspirations and methods. Briefly, Chinese poetry and American poetry around 1920s are obviously the typical instances of intertextuality, which seem interweaving, echoing and essentially intertextual.
\end{abstract} 1920s.

Key words - Intertextuality, Chinese poetry, American Poetry,

\section{Introduction}

Intertextuality is a term originating from the French word “intertextualité” that Julia Kristeva(1941- ) coined in 1967 in her noted "Word, Dialogue and Novel"[1]. Thanks to her, intertextuality today has gradually become a significant channel to examine literary works, anthropological ideas and even ethnical cultures in the western world. Comparatively speaking, Chinese scholars showed interest in the phenomenon of intertextuality much earlier than western scholars did. But intertextuality in China and in western countries is basically distinctive. In the view of Chinese scholars, intertextuality is, since Han Dynasty, "one of the figures of speech in rhetoric. The foregoing text and the following text are interactive and dispensing with each other while bringing up to full strength. The two texts reveal meaning individually, yet work mutually to convey a complete idea," as Chinese Cihai puts it[2]. Currently, readers at home and abroad incline to accept the western theory of intertextuality, which "insists that a text cannot exist as a hermetic or self-sufficient whole, and so does not function as a closed system"[3].

As for us, intertexutality exists to concern all sorts of texts, including those in various historical, cultural and linguistic contexts. And the texts are not individually isolated with each other, instead, they connect with each other, "echo" each other, influence each other, obtain meanings from each other, and function to facilitate the development of the world with each other. To some extent, we can claim that we live in a world of intertexutality, consciously or unconsciously. In this paper, we will associate intertextuality with poetic texts, i.e., Chinese and American poetry around 1920s. Like many observable texts, poetic texts are considered to be an important part of the objective beings, without ranks and authorities. And they are communicative because any poetic text is decorated with quotations while any poetic text is a result of absorbing and rearrangement of another text[4]. American poetic texts can not confine themselves within American culture and literature only, nor can Chinese poetic texts limit themselves in a small cosmos of Chinese culture and literature as well. So to speak, both American poetic texts and Chinese poetic texts live fundamentally in an interactive and intertextual atmosphere. Besides obtaining the influences from the social elements, taking European traditions for the formation of American poetry and Chinese poetic traditions for the appearance of "new poetry" as examples, they will experience the necessary courses of absorbing nourishments from each other, interpreting each other, supplementing each other, and seeking for refreshing energy or power from each other. Especially when they are confronted with literary or cultural dilemmas, this type of intertextual features will appear more transparent and unavoidable. Briefly, Chinese poetry and American poetry around 1920s are obviously the typical instances of intertextuality, which seem interweaving, echoing and essentially intertextual.

\section{An Intertextual View of American Poetry around 1920s}

\section{A. With Time Approaching to 1920s, European Traditions Still Function \\ Though America had already achieved its political independence through War of Independence(1776-1783), American culture and literature were not fairly independent in reality. Instead, European traditions continually had its epidemic power and potential influence. Religious beliefs and genteel thoughts, among other things, obviously played persistent roles in the sphere of American poetry writing. Studying the poems by Philip Freneau(1752-1832), Henry}

\footnotetext{
* This work is partially supported by Innovation Funds of Graduate Programs, Shaanxi Normal University; 2013 Visiting Scholar Exchange Program, Shaanxi Normal University; and the research programs attached to Ministry of Education of China (GPA 105004, 10YJA752031).
} 
Wordsworth Longfellow(1807-1882), Edgar Allan Poe(18091849), Robert Lee Frost(1874-1963), and the like, we still can observe the traces and remains of European styles and characteristics, one way or another. Even Ralph Waldo Emerson(1803-1882), a pioneering transcendentalist who established himself with high individualism and self-reliance in American spirits, could not completely break away from European heritages and philosophies, though "his harsh rhythms and striking images appeal to many modern readers as artful techniques"[5]. Poems of Walt Whitman(1819-1892) and Emily Dickinson(1830-1886) were undoubtedly the refreshing air in the development of American poetry, which also characterized themselves with the true American style. However, we cannot deny such a fact that both Whitman and Dickinson had ever immerged themselves in the sea of European classics and doctrines, and their works were indeed the outcomes of betraying and innovating the sustained European poetic customs. Essentially, the situation of this kind continued even in the 1920s as usual, though not obviously at times.

\section{B. Around 1920s, Chinese Classical Culture Competes with European Traditions}

Until 1920s when American Imagism extended its full wings and proclaimed a new era of American poetry, the links between the Old World and the New World were not basically cut off separately. The important poets of the 1920s like Ezra Loomis Pound(1885-1972) and Thomas Stearns Eliot(18881965) were willing to be the expatriates in Europe and keep an intimate relationship with European cultures. Pound was so qualified a foreign editor of Poetry in London, which turned out to be one important battlefield of American Imagists since 1912 while Eliot, attracted by the particular atmosphere of London, pursued his study there and finally joined in British nationality and converted his belief into Anglicanism. Nevertheless, at that time, the oriental cultures, especially Chinese culture, began to compete with European traditions to make American poetry nationalized.

Mentioning the role of Chinese culture and classical poetry in the development of American poetry around 1920s, we have to focus on Ezra Pound because it is Pound who valued and worshiped Chinese culture so highly and brought in America "the invasion of the Oriental spirits"[6]. In 1908, he got his first collection of poems, A Lume Spento, published in Europe, from which we still can see the traces of European cultures. Afterwards, Pound, together with Amy Lowell(18741925) and other imagists, "liberated American poetry from the strict rules of traditional English poetry by taking something useful from the classical Chinese poetry with its very formal rules"[7]. Meanwhile, he worked with "F.S. Flint, and other Imagists who were against the 'usually abstract, diffuse and sentimental' poetry of the genteel tradition” and established "the principles of Imagist poetry illuminated in 'A Few Don'ts"'[7]. But we'd better know that "it would be wrong if we think that traditional Chinese poetry was the only factor that started the Imagist movement" by considering "Japanese poetry such as haiku” and other literary elements[7]. Pound had never been to China, yet when he saw the translation notes and "The Chinese Written Character as a Medium for Poetry" by Ernest Fenollosa(1853-1908), he became hopelessly attracted by the beauty and "the artistic forms of traditional Chinese poetry”[6]. In 1914, Pound “translated” a shining collection of Chinese poems named Cathay, which aroused great interest among Pound's contemporaries. As M. Alexander ever commented, Cathy could be accepted as a brilliant book with striking images, perhaps "the most beautiful book in English” by valuing its transcendent beauty and grace between the lines. Pound, thus, was applauded as a talented American poet of a new era who had great discoveries for American modern poetry, i.e., the one who found "new Greece” for American “dreary” poetry through identifying the beauty of Chinese classical poetry[6].

Yet frankly, Pound's translation is not the traditional way we usually deal with. His translation, to some extent, can be taken as a rewriting, or a new interpretation of Chinese classical poetry, especially Chinese Tang poems. Here we'd like to quote one example. $\mathrm{Li} \operatorname{Po}(701-762)$, a well-known Chinese poet of Tang Dynasty, ever wrote a popular poem titled "The Jewel Stair's Grievance", which says that "The jeweled steps are already quite white with dew,/ It is so late the dew soaks my gauze stockings,/ And I let down the crystal curtain/ And watched the moon through the clear autumn.”[8] Literarily, the poem tells us that a lady, on a quiet but cold night, stands alone on the jeweled steps. It is so long time for her there that her stockings are soaked with dew. Then she enters her room, yet her loneliness and grievance follow her as usual. She then lets down the curtains to shut them out. However, nothing can help her but make her more restless. Thus she and the cold moon watch each other alone. Based on this poem, Pound, by referring to Fenollosa's notes, "translated" a new poem titled "A Girl”, which says that "The tree has entered my hands,/ The sap has ascended my arms,/ The tree has grown in my breast-/ Downward,/ The branches grow out of me, like arms./ Tree you are, Moss you are,/ You are violets with wind above them./ A child-so high-you are,/ And all this is folly to the world."[9] Chinese readers may not be satisfied with Pound's translation here, which seems not "qualified” enough by taking "word accuracy” into account. However, this translation stirred huge enthusiasm among American readers because they assumed that Pound had grasped the brilliant points of Li Po's literary implications and had made a wise transformation of its theme in accordance to the principles of Imagist poetry.

Pound was certainly a monumental figure who embodied Chinese classical aesthetic images into his modern American poetry and used Chinese classical poetry to "fight" against European traditions. He was also a representative model to take in Chinese classical quintessence but he was surely not the only one. Virtually, around 1920s, many poets, inspired by Pound, began to show their interest in Chinese classical poetry. Edgar Lee Masters(1868-1950), Amy Lowell(1874-1925), Carl Sandburg(1878-1967), Vachel Lindsay(1879-1931), John Gould Fletcher(1886-1950), to name a few, were those who 
opened a new era for American modern poetry and brought in an eternal influence upon the coming literary schools in the western world.

\section{An Intertextual View of Chinese Poetry around 1920s}

A. With Time Approaching to 1920s, China Sustains her Poetic Traditions Continually

In essence, Chinese poetry is initially intertextual within its own system. Chinese poetry, tracing back to its origin, The Book of Songs, had gone through thousands of years in history. And the thousand-year-long poetic traditions were deeply rooted in the hearts of Chinese poets from generation to generation. The appearance of Qu Yuan(340 B.C.-278 B.C.) and his masterwork, "Li Sao", undoubtedly promised a new era of Chinese poetry with its "simplicity", "reservation", "nobleness" and "straightness"[10]. With the advancement of the poetic traditions, poetry in Tang Dynasty perhaps reached the highest summit of its form and style though "it may not be the final destination of Chinese classical poetry"[10]. Li Po, Meng Haoran(689/691-740), Wang Wei(701-761), Tu $\mathrm{Fu}(712-770)$, Meng Jiao(751-814), Han Yu(768-824), Bai Juyi(772-846), Liu Zongyuan(773-819), Jia Dao(799-843), Du Mu(803-852), etc., made Tang Poems obsessed with magnificence and beauty, which finally set perfect models for the coming eras. The popularity of $\mathrm{Ci}$ in Song Dynasty seemed to open a new channel of viewing human world as well as human feelings with its glamour and ingenuity, but the innovation was carried on "without questioning the inherent system of aesthetic appreciation and the conventional ways of displaying emotions”[10]. Even in Ming Dynasty and Qing Dynasty, the charming features of Tang Poems and Song Ci were still overwhelmingly prevailing, which appeared that no new poetic beings could surpass them. Fundamentally, although Chinese poetry had experienced numerous and influential artistic evolutions in thousands of years' history, "its inherent spirits and artistic thoughts proceed stably and coherently, so to speak, there is no true and practical change against its well-established traditions throughout the years”[10]. Western cannons and fires afterwards bloodily weakened and endangered Chinese nation and made them reconsider the stable existence of Chinese classical poetry traditions that seemed far from people's real life. Poets at that time thought ways out. Huang Zunxian(1848-1905), a daring and brilliant poet of Qing Dynasty, announced that "I write as I say", which advocated to bring poetry writing from the "noble temple" to the "earthly world". Correspondingly, Liang Qichao(1873-1929), an ambitious and patriotic scholar, then explicitly promoted the "revolution in poetry" with unprecedented vigor, aiming to rescue the decaying national situations through "new expressions" and "new ideas". However, both Huang Zunxian and Liang Qichao only "emphasized the new content and new consciousness in the poetry they stood for while retaining its traditional artistic form"[7], which can be quoted as a common artistic symptom of the scholars and poets before $\mathrm{Hu}$ Shih(1891-1962) took literary actions.
B.Around 1920s, Western Culture, Especially American Culture, Influenced Chinese Poetic Traditions

Around 1920s, there were Chinese scholars assigned by Chinese government to go to America to learn advanced technology and inspiring knowledge for the sake of national rejuvenation. Among the promising youths, $\mathrm{Hu}$ Shih was a representative pioneer who later brought great contributions to the practical revolution of Chinese classical poetry. As one of the earliest Chinese overseas students in America and a talented disciple of John Dewey(1859-1952), Hu Shih ever studied at Cornell University and Columbia University from 1910 to 1917 . He had a keen perception and careful study of Chinese classical poetry and found that Chinese poetic traditions, in the complicated international situations of his time, was lack of liveliness and pragmatic spirits, indeed, "too rigid to express fully one's ideas and feelings"[7]. Under the influence of Dewey and his pragmatic teachings, $\mathrm{Hu}$ Shih "launched a revolution in literature" in 1915 and "attempted his literary experiment by writing poetry in the vernacular free verse"[7], which could be recognized as "a huge liberation of poetic forms"[11]. He got the inspiration from the books he read in Ithaca of America, and "unconsciously, became affected" in style and thoughts[11]. Apart from the truth above, he also informed us that Chinese people maybe had to refer to Western literature and study how their achievements came into being because Chinese literature at that time was much similar to European literature three or four hundred years ago. Thus identifying "live literature" from "dead literature" might keep us from adhering to the past practices and instead help us breathe courage[11]. To demonstrate his determination in Chinese poetic revolution, he had his Experimental Poems published in 1920 though he was actually so good at writing classical forms of Chinese poetry as we can see from his Collection of Memorable Poems in 1916[11]. It is true that Experimental Poems exists basically as "a first volume of vernacular free verse that had a far-reaching impact on Chinese poetry"[7]. Like Pound who adopted Imagists' principles into his translation of Cathy, $\mathrm{Hu}$ Shih wrote his vernacular free verse through observing his own poetic principles: "first, to avoid empty talk; second, to be particular about grammar; and third, to use 'vernacular' whenever necessary....”[11] No wonder Yuan Kejia(1921-2008) ever commented that "The Imagists had left their foot prints on $\mathrm{Hu}$ Shih's Experimental Poems"[7]. Additionally, "among other factors which led to his success was his introduction of English and American poetries to China, an act vitally important in modernizing the traditional Chinese poetry"[7]. The English and American poems that he translated into Chinese include George G. Byron’s “The Isles of Greece”, F. Scott Fitzgerald’s "Heart's Desire”, Sara Teasdale's “Over the Roofs”, Lady Anne Lindsay's “Auld Robin Gray”, etc. Besides practicing writing vernacular free verse like "Experimental Poems", "The Butterfly”, “The Mid-autumn Day”, etc., Hu Shih also made his translation in accordance with his writing principles. Here comes one particular example. Sara Teasdale(1884-1933) had a poem titled "Over the Roofs" which goes like this, "I said, 'I 
have shut my heart,/ As one shuts an open door,/ That Love may starve therein/ And trouble me no more.'/ But over the roofs there came/ The wet new wind of May,/ And a tune blew up from the curb/ Where the street-pianos play./ My room was white with the sun/ And Love cried out in me,/ 'I'm strong, I will break your heart/Unless you set me free."' When translating it, Hu Shih did not use the same poetic style as he translated Byron's “The Isles of Greece”. Consciously and carefully, he experimented to use the vernacular free verse to make almost word-to-word translation, which looks completely non-classical. It seemed that $\mathrm{Hu}$ Shih was so satisfied with his own translation that he took it as "an epochmaking piece to my 'new poetry' writing”[7,11]. Likewise, his translations of Fitzgerald's “Heart's Desire”, Lindsay's “Auld Robin Gray", etc., are all perfectly matched with his literary declaration of "The Eight Don'tsisms"-“Don't quote from classics; Don’t use cliché expressions; Don’t use antithesis; Don't avoid using common sayings; Don't be ungrammatical; Don't be sentimental; Don't imitate classical writers; Don't be vague.”[7,12] Influenced by $\mathrm{Hu}$ Shih as well as the western poetic style, a lot of Chinese scholars attempted to write "new poetry" and thus became "new poets" around 1920s. Specifically, the poets include, but are not limited to, Liu Bannong (1981-1934), Shen Yimo (1883-1971), Xu Zhimo (1896-1931), Kang Baiqing (1896-1945), Fu Sinian (18961950), Wen Yiduo (1899-1946), Yu Pingbo (1900-1990), Liang Shiqiu (1903-1987), Ye Gongchao (1904-1982), etc. Since then, Chinese vernacular free verse, i.e., "Chinese new poetry", gradually became an overwhelming literary current.

\section{Conclusion}

Through analyzing the literary phenomena above, we can figure out that American poetry is intertextual, lying in the fact that with time approaching to 1920s, European traditions still function in the transformation of American poetry. And around 1920s, Chinese classical culture competes with European traditions to make American poetry nationalized. Meanwhile, with time approaching to 1920 s, as we can see, China sustains her poetic traditions continually through referring to the established achievements in the past. And around 1920s, western culture, especially American culture, influenced Chinese poetic traditions to have a change in both inspirations and methods.

To sum up, on the way of the literary development, American poetry and Chinese poetry have intertextually experienced various courses to guarantee their final evolvements and successful transformations. Certainly, the facts the paper has quoted are essentially only a small part of the complicated intertextual beings. Nevertheless, the paper here means to conduct an intertextual way of analysis to proclaim a different angle of viewing American poetry and Chinese poetry around 1920s, and examining their intertextual possibilities, connections and features.

\section{References}

[1] J. Wang, Intertextuality, Guilin: Guangxi Normal University Press, 2005, pp. 1-2.

[2] Cihai, Compact ed., Shanghai: Shanghai Lexicographical Publishing House, 1999, p. 42.

[3] J. Still and M. Worton, "Introduction," in Intertextuality: Theories and Practices, M. Worton \& J. Still, Eds. N. Y.: St. Martin’s Press, Inc., 1990, pp.1-2.

[4] J. Kristeva, "Word, Dialogue and Novel," in The Kristeva Reader, Toril moi, Ed., Oxford: Blackwell Publiser Ltd., 1986, p. 36.

[5] W.R. Wu, Ed., History and Anthropology of American Literature, Vol. 1, Foreign Language Teaching and Research Press, 2007, pp. 162-163.

[6] Y.H. Zhao, Woden Travels Afar, Shanghai: Shanghai Translation Publishing House, 2003, pp. 17-19, .

[7] Z.Q. Zhang, "Does Poetry Make Anything Happen?-A Dialogue between Chinese and American Poets in the 20th Century,” Proceedings of 20th-century American Poetry International Academic Conference, 2007, pp. 64-65, 59-60, .87-88.

[8] W. Wang and Y.J. Guo, Modern American Poetry, Ed., Xi'an: Shaanxi Normal University General Publishing House Co., Ltd., 2012, pp. 30-31.

[9] J. Tao, Selected Readings in American Poetry, Beijing: Peking University Press, 2008, pp. 60-62.

[10] M. Xie, "Foreword: On Chinese New Poetry," History of One-hundredyear Chinese New Poetry, Z.C. Hong, Ed., Beijing: Peking University Press, 2010, pp. 2-3.

[11] Hu Shih, "Preface," Experimental Poems, pp. 24, 12, 20, 113-114, 15, 27-28.

[12] S. Hu, "I Was Forced to Make Revolutions: a Beginning of the Literary Revolution,” Anthology of Hu Shih: Poetry, Fiction, Drama \& Biography, Beijing: Yanshan Publishing House, 1995, pp. 241-242. 